\title{
Therapeutic effect of intratumoral injections of dendritic cells for locally recurrent gastric cancer: a case report
}

\author{
Masanori Kobayashi ${ }^{1,6}$, Tomoyo Sakabe $^{1}$, Asako Chiba ${ }^{2}$, Akihito Nakajima ${ }^{2}$, Masato Okamoto ${ }^{3}$, Shigetaka Shimodaira ${ }^{4}$, \\ Yoshikazu Yonemitsu ${ }^{5}$, Yuta Shibamoto ${ }^{6}$, Noboru Suzuki ${ }^{7}$, Masaki Nagaya ${ }^{2,7^{*}}$ and The DC-vaccine study group at the \\ Japan Society of Innovative Cell Therapy (J-SICT)
}

\begin{abstract}
An 80-year-old man with a history of gastric cancer and pulmonary emphysema underwent a distal gastrectomy for gastric cancer in 1997. In 2010, an endoscopic examination revealed a depressed-type lesion at the oral side of the anastomosis, which was diagnosed as signet-ring adenocarcinoma. Surgical management was considered, but was rejected because of obstructive and restrictive respiratory events. Chemotherapy was terminated because of adverse events. Endoscopy was used to administer intratumoral injections of dendritic cells (DCs) targeting synthesized peptides of Wilms tumor 1 (WT1) and mucin 1, cell-surface associated (MUC1). An immunohistochemical analysis of the tumor samples indicated positivity for WT1 and MUC1. One month after seven cycles of DC had been administered (between November 2010 and April 2011), no suspicious lesions were evident, and his biopsy results were normal. The patient has been in remission for 30 months. Intratumoral injections of DCs showed therapeutic effects in this patient, who could not undergo endoscopic submucosal dissection or surgery.
\end{abstract}

Keywords: Dendritic cell, WT1, MUC1, Immunotherapy and recurrent gastric cancer

\section{Background}

Gastric cancers are the second most common cause of cancer-related deaths worldwide [1]. Although surgery is the definitive treatment for gastric cancers, alternative therapeutic modalities include endoscopic submucosal dissection (ESD), chemotherapy, and radiation therapy.

Recently, it has been reported that half of all malignancies occur in patients aged over 70 years [2]. Chronic obstructive pulmonary disease (COPD), which is characterized by airflow limitation, is also common in elderly individuals [3]. In some cases, standard therapy for malignancies is not suitable because of the presence of COPD. Sakai et al. [4] showed that COPD was an independent risk factor for intra- and post-operative pulmonary events. In addition, Dimopoulou et al. [5] reported that some

\footnotetext{
*Correspondence: m2nagaya@marianna-u.ac.jp

${ }^{2}$ Seren Clinic Tokyo, Isokai, 2-10-2 Shirokanedai, Minato-ku, Tokyo 108-0071, Japan

7Department of Immunology, St Marianna University School of Medicine, 2-16-1 Sugao Miyamae-ku, Kawasaki 261-8511, Japan

Full list of author information is available at the end of the article
}

anti-cancer drugs induce pulmonary toxicity. For example, paclitaxel, docetaxel, and irinotecan have been reported to cause non-specific interstitial pneumonitis. In some cases, minimally invasive therapy might be required for elderly patients with COPD.

Dendritic cells (DCs) are antigen-presenting cells that are specialized for the initiation of T-cell immunity $[6,7]$. DC-based immunotherapy that targets synthesized peptides has recently been used for various malignancies, including gastric cancer [8-11]. The appropriate selection of synthesized peptides is necessary to enhance the therapeutic effect of DC-based immunotherapy for gastric cancer. In 2009, the cancer antigen prioritization project of the National Cancer Institute ranked Wilms tumor 1 (WT1) and mucin 1, cell-surface associated (MUC1) as the highest and second highest priority antigens, respectively [12]. As determined by immunohistochemistry (IHC), the expressions of WT1 and MUC1 in gastric cancers were found to be 42 to $53 \%$ [13] and 93\% [14], respectively. 
Intratumoral administration using DC phagocytosis is a potential favorable option [15]. We used esophagogastroduodenoscopy (EGD) to administer intratumoral injections of DCs pulsed with WT1 and MUC1.

\section{Case presentation}

An 80-year-old man with a history of gastric cancer and pulmonary emphysema underwent a Billroth I distal gastrectomy for early gastric cancer in 1997. In 2005 and 2009, he was referred for an endoscopic mucosal resection of local gastric cancer recurrence (well-differentiated tubular adenocarcinoma). In May 2010, he underwent a followup EGD that revealed a depressed-type lesion $(10 \times 18 \mathrm{~mm}$ in size) on the body of stomach near the anastomosis (O) (Figure 1a). A histopathological analysis of the biopsy samples revealed signet-ring adenocarcinoma (Figure 2a-a"). A computed tomography scan revealed no metastasis. Although total resection of the gastric remnant is a potentially curative therapy, this surgery was not performed in consideration of the patient's lung dysfunction, which included obstructive and restrictive pulmonary disease (vital capacity (VC): $2.12 \mathrm{~L}$; \%VC: 71.9\%; forced expiratory volume in 1.0 seconds: $42.9 \%$ ). The patient had a 50 -year history of smoking. ESD was contraindicated because the cancer was of an undifferentiated type. Therefore, treatment with TS-1 (tegafur, gimeracil, and oteracil potassium; Taiho Pharmaceutical Co, Ltd, Tokyo, Japan) was initiated in August 2010. Four weeks after TS-1 administration, treatment-related anorexia (grade 2; Common Terminology Criteria for Adverse Events, version 4.0) was observed, and hence, chemotherapy was discontinued at the request of the patient.

The methods that were used for DC preparation have been described previously [16]. The DCs were pulsed with major histocompatibility complex (MHC)-I-restricted WT1 peptide antigens, according to the patient's human leukocyte antigen (HLA)-A pattern (HLA-A 2402; CYTWNQMNL (mutant WT1 peptide, Neo-MPS, San Diego, California, United States) and MUC1 long peptide (30 mer at $20 \mathrm{mg} / \mathrm{mL}$; TRPAPGSTAPPAHGVTSAPDTRPAPGSTAP; Greiner Japan, Tokyo, Japan)). The DCs were characterized using flow cytometry to ensure that they achieved the typical phenotype of mature DCs. The surface molecules that were expressed by the DCs were determined. The phenotype CD $14^{-/ \text {low }} / \mathrm{HLA}_{-} \mathrm{DR}^{+} / \mathrm{HLA}-$ $\mathrm{ABC}^{+} / \mathrm{CD} 80^{+} / \mathrm{CD} 3^{+} / \mathrm{CD} 86^{+} / \mathrm{CD} 40^{+} / \mathrm{CCR}^{+}$was considered to define mature DCs. The DCs were cryopreserved until the day of administration. The DC suspension was adjusted to a total volume of $1.0 \mathrm{~mL}$ with saline.

Six months after the gastric cancer recurrence had been diagnosed, intratumoral injections of DCs were administered using EGD between November 2010 and April 2011. This treatment was approved by the institutional review board of Isoukai (approval number: 26-1) and was conducted in accordance with the Declaration of Helsinki.

Vaccinations were repeated seven times at two to eightweek intervals (approximately $2.99 \times 10^{7}$ cells/injection; the first four vaccinations at two-week intervals and the last three vaccinations at four- to eight-week intervals). A needle was used (diameter $25 \mathrm{G}$, length $4 \mathrm{~mm}$ ) to administer DCs at four submucosal layer sites around the tumor. Subsequently, we administered OK432 (1-3KE) dissolved in $0.5 \mathrm{~mL}$ saline at two sites in the submucosal layer around the tumor. DC therapy was well tolerated and the only treatment-related adverse event was fever, with a body temperature of over $38^{\circ} \mathrm{C}$ for two days after the fourth vaccination. One month after the final administration, the gastric cancer was found to have regressed

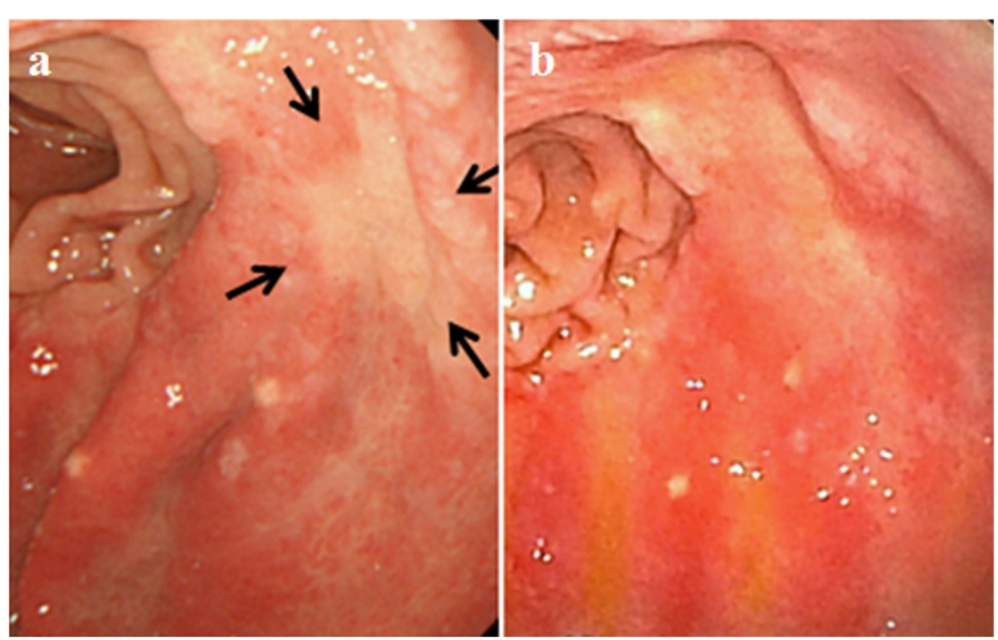

Figure 1 Esophagogastroduodenoscopy (EGD) images. (a, b) Type 0 -llc lesion $(10 \times 18 \mathrm{~mm}$ in size) on the body of the stomach near the anastomotic region $(\mathrm{O})$ before vaccination (a). The gastric cancer regressed to an obscure lesion one month after the final cycle of treatment (b). Arrows indicate the location of the cancer. 


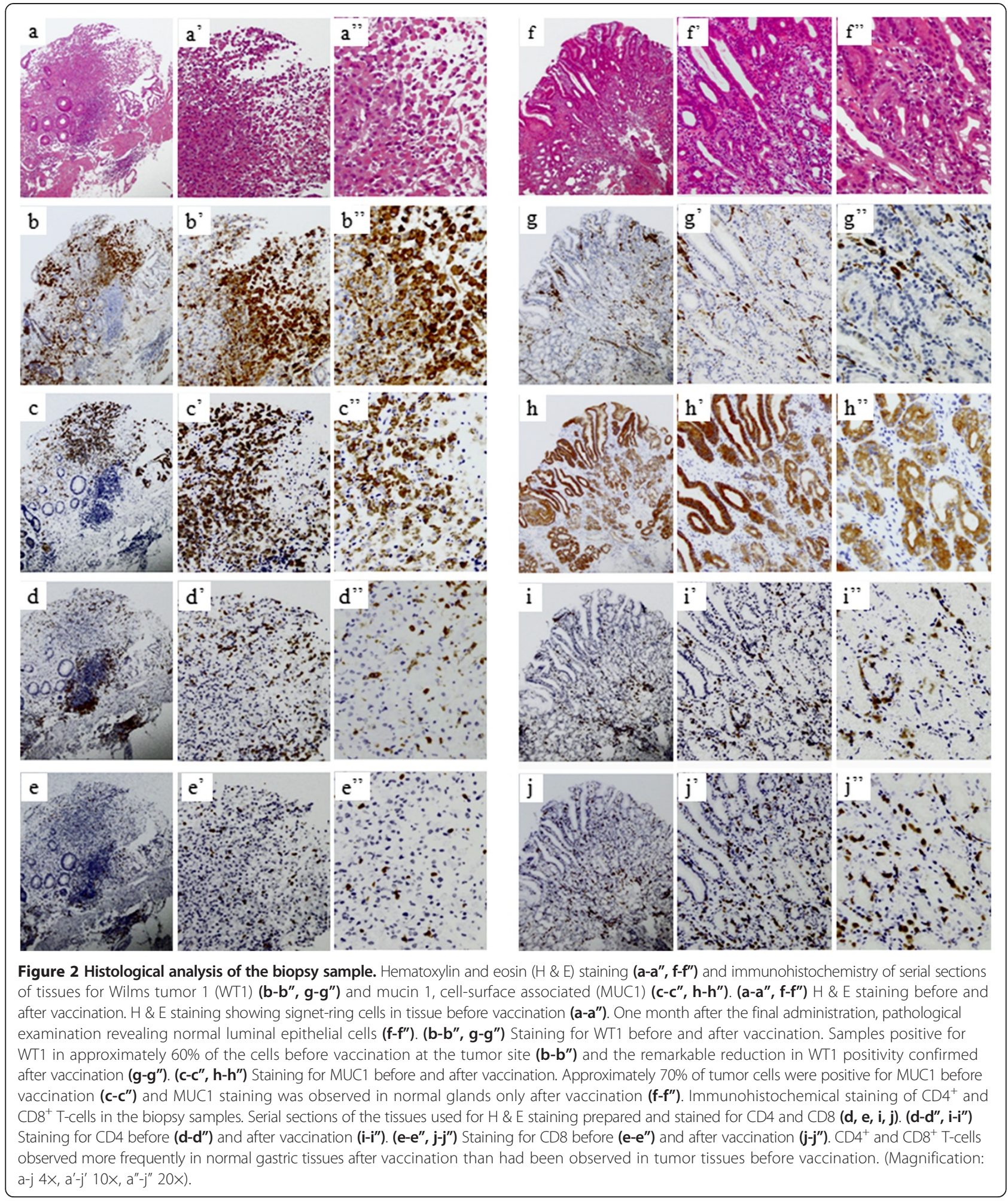

completely (Figure 1b). A histopathological examination of the biopsy samples revealed no signet-ring cells (Figure 2f-f"). During the 30 months following DCbased immunotherapy, no pathological recurrence has been observed. Laboratory data indicated reductions in carcinoembryonic antigen and carbohydrate antigen 19-9 levels after DC therapy, which decreased from 8.2 to $6.8 \mathrm{ng} / \mathrm{mL}$ (normal range: $<5.0 \mathrm{ng} / \mathrm{mL}$ ) and from 33.2 to $24.7 \mathrm{U} / \mathrm{mL}$ (normal range: $<37.0 \mathrm{U} / \mathrm{mL}$ ), respectively. 
IHC for WT1 (Monoclonal 6 F-H2, Dako Cytomation, Carpinteria, California, United States) [13] and MUC1 (Becton Dickinson Labware; Franklin Lakes, New Jersey, United States) was performed as previously described [17], with a few modifications. IHC results were positive for WT1 in approximately $60 \%$ of signet ring cells before vaccination (Figure 2b-b"); however, the number of cells staining positive was remarkably reduced after vaccination (Figure 2g-g"). Approximately 70\% of cells were positive for MUC1 before vaccination (Figure 2c-c"). After vaccination, remodeling was confirmed at the site of malignant cells, and MUC1 positivity was observed only in the normal glands (Figure $2 \mathrm{~h}-\mathrm{h}$ ").

No increases in the proportions of $\mathrm{CD}^{+}$and $\mathrm{CD}^{+} \mathrm{T}$ cells were noted in the peripheral blood, based on assessments performed before and after vaccination $\left(\mathrm{CD}^{+}{ }^{+} \mathrm{T}\right.$ cells: 43.9 to $42.5 \%$; $\mathrm{CD}^{+}$T-cells: 29.3 to $\left.25.5 \%\right)$. On the other hand, $\mathrm{CD}_{4}^{+}$and $\mathrm{CD}^{+}$T-cells were observed more frequently in the normal gastric tissue after vaccination (Figure 2i-i", j-j") than they had been observed in the tumor tissues before vaccination (Figure $2 \mathrm{~d}-\mathrm{d}$ ", e-e").

The frequency of WT1-specific cytotoxic T lymphocytes (CTLs) increased from 0.03 to $0.08 \%$. The method used has been described in our previous report [16]. At 31 months after the final vaccination, the levels of WT1-specific CTLs remained high $(0.10 \%)$ (Figure 3a-c).

\section{Discussion}

In this case, restrictive pulmonary disease led the primary oncologist to opt for chemotherapy instead of surgery. However, the patient developed intolerable chemotherapyassociated anorexia, which necessitated the discontinuation of treatment. Since a few previous studies have indicated that DC immunotherapy could be safely administered to cancer patients as a minimally invasive treatment $[8,9,18]$, we chose this therapy for our patient. The direct injection of DCs into tumors has been investigated in clinical studies, including those on hepatoma [19], pancreatic cancer [20], and gastric cancer [21]. Wen et al. [22] compared the therapeutic immunity achieved by several modes of DC injection, including intratumoral, intranodal, intravenous, and subcutaneous injections in mice. The survival rates were dramatically increased by vaccination via intratumoral injection, as compared with injections performed using other delivery methods. Pellegatta et al. [23] reported that, in comparison with other delivery methods, intratumoral injection of DCs may increase antitumor efficacy by altering the intratumoral environment and increasing T-cell-mediated immune responses. In this case, increased WT1-specific CTL levels were observed after DC immunotherapy, indicating that the DCs presented WT1 to naïve $\mathrm{CD} 8^{+} \mathrm{T}$-cells in a precise manner. We suggest that gastric cancer could be a good indication for the direct injection of DCs and that the appropriate site for injection can be selected using live imaging with EGD.

Immature DCs were used for direct injections in previous studies because their phagocytic ability has been considered to be superior to that of mature DCs [24]. However, immature DCs have been shown to induce tolerance and the antigen-specific inhibition of effector T-cell function $[25,26]$. Drutman and Trombetta [27] showed that mature DCs retained a robust capacity to capture soluble antigens. Furthermore, antigens internalized by mature DCs were efficiently presented on MHC class II cells and crosspresented on MHC class I cells. De Vries et al. [28] demonstrated that mature DCs efficiently migrate into T-cell-populated areas of the lymph nodes of melanoma patients. Taken together, these findings suggest that it might be reasonable to use mature DCs for direct injections into tumors.

IHC results for WT1 and MUC1 indicated significant changes after vaccination. Mucin is a high molecular weight glycoprotein that plays an important role in protecting the gastrointestinal tract epithelium and is normally present in abundance on the luminal surface of various secretory epithelial cells. The core peptides in the tandem repeat domain are masked in normal cells and exposed in cancer

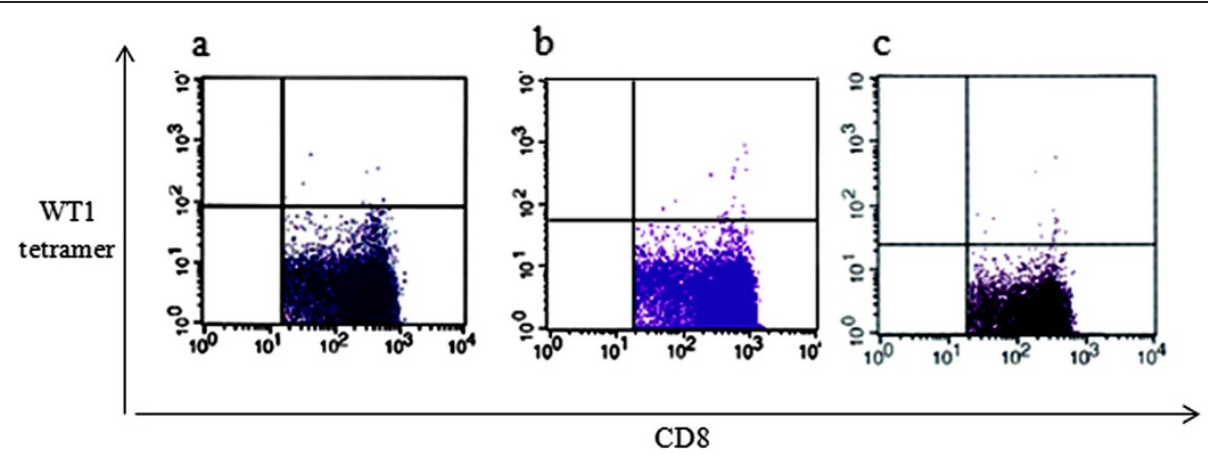

Figure 3 Analysis of Wilms tumor 1 (WT1)-specific cytotoxic T lymphocytes (CTLs). (a) Before vaccination. (b) After vaccination. (c) At 31 months after the final vaccination. WT1-specific CTL levels before vaccination increased from 0.03 (a) to $0.08 \%$ at the final vaccination (b). At 31 months after the final vaccination, WT1-specific CTL levels increased to $0.10 \%$ (c). 
cell-associated mucins. CTLs for MUC1 only attack cancer cells with exposed tandem repeat domains [29]. In this case, MUC1-positive cells were present on the surface of the signet-ring adenocarcinoma before vaccination (Figure 2c-c"); however, MUC1-positive cells were only confirmed on normal luminal epithelial cells after DC immunotherapy, as we had expected (Figure $2 \mathrm{~h}-\mathrm{h}$ ").

\section{Conclusions}

To the best of our knowledge, this is the first report on the therapeutic effects of DCs that target synthesized peptides in a patient with gastric cancer who could not undergo ESD or curative surgery.

\section{Consent}

We provided precise explanations of the therapy to the patient and his family. They gave written informed consent for the publication of this case report and any accompanying images. A copy of the written consent is available for review by the Editor-in-Chief of this journal.

\section{Abbreviations}

COPD: Chronic obstructive pulmonary disease; CTLs: Cytotoxic T lymphocytes; DC: Dendritic cell; EGD: Esophagogastroduodenoscopy; HLA: Human leukocyte antigen; IHC: Immunohistochemistry; MUC1: Mucin 1, cell-surface associated; WT1: Wilms tumor 1 .

\section{Competing interests}

The authors have no financial or personal relationships with people or organizations that could inappropriately influence this work.

\section{Authors' contributions}

MK and MN conceived and designed the study and collected, assembled, analyzed, and interpreted the data. TS, AC, AN, MO, SS, YY, YS, and NS interpreted the data. MK and MN wrote the manuscript and approved the final manuscript. All authors read and approved the final manuscript.

\section{Authors' information}

MK is a director of Seren Clinic. MN is a staff assistant at the Department of Gastrointestinal Surgery, Kanagawa Cancer Center, a director of Seren Clinic, and a professor at the Department of Immunology, St Marianna University School of Medicine. TS, AC, and AN were staff assistants at Seren Clinic. MO, SS, YY, YS, and NS are also professors at each university.

\section{Acknowledgements}

We acknowledge the patient who agreed to participate in this study and his primary oncologists. This study received no financial support.

\section{Author details}

${ }^{1}$ Seren Clinic Nagoya, Isokai, 4-14-2 Sakae, Naka-ku, Nagoya 460-0008, Japan. ${ }^{2}$ Seren Clinic Tokyo, Isokai, 2-10-2 Shirokanedai, Minato-ku, Tokyo 108-0071, Japan. ${ }^{3}$ Institute for Advanced Medical Research, Keio University School of Medicine, 35 Shinanomachi Shinjuku, Tokyo 160-8582, Japan. ${ }^{4}$ Cell Processing Center, Shinshu University Hospital, 3-1-1 Asahi, Matsumoto, Nagano 390-8621, Japan. ${ }^{5}$ R \& D Laboratory for Innovative Biotherapeutics, Graduate School of Pharmaceutical Sciences, Kyushu University, 3-1-1 Maidashi, Higashi-ku, Fukuoka 812-8582, Japan. 'Department of Radiology, Nagoya City University Graduate School of Medical Sciences, 1 Kawasumi, Mizuho-cho, Mizuho-ku, Nagoya 467-8601, Japan. ${ }^{7}$ Department of Immunology, St Marianna University School of Medicine, 2-16-1 Sugao Miyamae-ku, Kawasaki 261-8511, Japan

Received: 7 June 2014 Accepted: 3 December 2014

Published: 19 December 2014

\section{References}

1. Hartgrink HH, Jansen EP, van Grieken NC, van de Velde CJ: Gastric cancer. Lancet 2009, 374:477-490.

2. Extermann M, Boler I, Reich RR, Lyman GH, Brown RH, DeFelice J, Levine RM Lubiner ET, Reyes P, Schreiber FJ 3rd, Balducci L: Predicting the risk of chemotherapy toxicity in older patients: the Chemotherapy Risk Assessment Scale for High-Age Patients (CRASH) score. Cancer 2012, 118:3377-3386.

3. Decramer M, Janssens W, Miravitlles M: Chronic obstructive pulmonary disease. Lancet 2012, 379:1341-1351.

4. Sakai RL, Abrão GM, Ayres JF, Vianna PT, Carvalho LR, Castiglia YM: Prognostic factors for perioperative pulmonary events among patients undergoing upper abdominal surgery. Sao Paulo Med J 2007, 125:315-321.

5. Dimopoulou I, Bamias A, Lyberopoulos P, Dimopoulos MA: Pulmonary toxicity from novel antineoplastic agents. Ann Oncol 2006, 17:372-379.

6. Banchereau J, Steinman RM: Dendritic cells and the control of immunity. Nature 1998, 392:245-252.

7. Gabrilovich D: Mechanisms and functional significance of tumour-induced dendritic-cell defects. Nat Rev Immunol 2004, 4:941-952.

8. Aarntzen EH, Schreibelt G, Bol K, Lesterhuis WJ, Croockewit AJ, de Wilt JH, van Rossum MM, Blokx WA, Jacobs JF, Duiveman-de Boer T, Schuurhuis DH, Mus R, Thielemans K, de Vries IJ, Figdor CG, Punt CJ, Adema GJ: Vaccination with mRNA-electroporated dendritic cells induces robust tumor antigenspecific CD4+ and CD8+ T cells responses in stage III and IV melanoma patients. Clin Cancer Res 2012, 18:5460-5470.

9. Kantoff PW, Higano CS, Shore ND, Berger ER, Small EJ, Penson DF, Redfern CH, Ferrari AC, Dreicer R, Sims RB, Xu Y, Frohlich MW, Schellhammer PF, IMPACT Study Investigators: Sipuleucel-T immunotherapy for castration-resistant prostate cancer. N Engl J Med 2010, 363:411-422.

10. Kono K, Takahashi A, Sugai H, Fujii H, Choudhury AR, Kiessling R, Matsumoto Y: Dendritic cells pulsed with HER-2/neu-derived peptides can induce specific T-cell responses in patients with gastric cancer. Clin Cancer Res 2002, 8:3394-3400.

11. Sadanaga N, Nagashima H, Mashino K, Tahara K, Yamaguchi H, Ohta M, Fujie T, Tanaka F, Inoue H, Takesako K, Akiyoshi T, Mori M: Dendritic cell vaccination with MAGE peptide is a novel therapeutic approach for gastrointestinal carcinomas. Clin Cancer Res 2001, 7:2277-2284.

12. Cheever MA, Allison JP, Ferris AS, Finn OJ, Hastings BM, Hecht TT, Mellman I, Prindiville SA, Viner JL, Weiner LM, Matrisian LM: The prioritization of cancer antigens: a national cancer institute pilot project for the acceleration of translational research. Clin Cancer Res 2009, 15:5323-5337.

13. Nakatsuka S, Oji Y, Horiuchi T, Kanda T, Kitagawa M, Takeuchi T, Kawano K, Kuwae Y, Yamauchi A, Okumura M, Kitamura Y, Oka Y, Kawase I, Sugiyama H, Aozasa K: Immunohistochemical detection of WT1 protein in a variety of cancer cells. Mod Pathol 2006, 19:804-814.

14. Hwang I, Kang YN, Kim JY, Do YR, Song HS, Park KU: Prognostic significance of membrane-associated mucins 1 and 4 in gastric adenocarcinoma. Exp Ther Med 2012, 4:311-316.

15. Song S, Zhang K, You H, Wang J, Wang Z, Yan C, Liu F: Significant anti-tumour activity of adoptively transferred $T$ cells elicited by intratumoral dendritic cell vaccine injection through enhancing the ratio of CD8(+) T cell/regulatory $\mathrm{T}$ cells in tumour. Clin Exp Immunol 2010, 162:75-83.

16. Kimura $Y$, Tsukada J, Tomoda T, Takahashi H, Imai K, Shimamura K, Sunamura M, Yonemitsu Y, Shimodaira S, Koido S, Homma S, Okamoto M: Clinical and immunologic evaluation of dendritic cell-based immunotherapy in combination with gemcitabine and/or S-1 in patients with advanced pancreatic carcinoma. Pancreas 2012, 41:195-205.

17. Lau SK, Weiss LM, Chu PG: Differential expression of MUC1, MUC2, and MUC5AC in carcinomas of various sites: an immunohistochemical study. Am J Clin Pathol 2004, 122:61-69.

18. Kobayashi M, Sakabe T, Abe H, Tanii M, Takahashi H, Chiba A, Yanagida E, Shibamoto Y, Ogasawara M, Tsujitani S, Koido S, Nagai K, Shimodaira S, Okamoto M, Yonemitsu Y, Suzuki N, Nagaya M, DC-vaccine study group at the Japan Society of Innovative Cell Therapy (J-SICT): Dendritic cell-based immunotherapy targeting synthesized peptides for advanced biliary tract cancer. J Gastrointest Surg 2013, 17:1609-1617.

19. Chi KH, Liu SJ, Li CP, Kuo HP, Wang YS, Chao Y, Hsieh SL: Combination of conformal radiotherapy and intratumoral injection of adoptive dendritic cell immunotherapy in refractory hepatoma. J Immunother 2005, 28:129-135.

20. Hirooka Y, Itoh A, Kawashima H, Hara K, Nonogaki K, Kasugai T, Ohno E, Ishikawa T, Matsubara H, Ishigami M, Katano Y, Ohmiya N, Niwa Y, 
Yamamoto K, Kaneko T, Nieda M, Yokokawa K, Goto H: A combination therapy of gemcitabine with immunotherapy for patients with inoperable locally advanced pancreatic cancer. Pancreas 2009, 38:e69-e74.

21. Kanazawa M, Yoshihara K, Abe H, Iwadate M, Watanabe K, Suzuki S, Endoh Y, Ohki S, Takita K, Sekikawa K, Takenoshita S, Takagi T, Irisawa A, Sato Y, Ogata T, Ohto $\mathrm{H}$ : Case report on intra-tumor injection therapy of dendritic cells in advanced gastric cancer. Gan To Kagaku Ryoho 2004, 31:1773-1776.

22. Wen CC, Chen HM, Chen SS, Huang LT, Chang WT, Wei WC, Chou LC, Arulselvan P, Wu JB, Kuo SC, Yang NS: Specific microtubule-depolymerizing agents augment efficacy of dendritic cell-based cancer vaccines. J Biomed Sci 2011, 18:44.

23. Pellegatta S, Poliani PL, Stucchi E, Corno D, Colombo CA, Orzan F, Ravanini M, Finocchiaro G: Intra-tumoral dendritic cells increase efficacy of peripheral vaccination by modulation of glioma microenvironment. Neuro Oncol 2010, 12:377-388.

24. Mann DL, Celluzzi CM, Hankey KG, Harris KM, Watanabe R, Hasumi K: Combining conventional therapies with intratumoral injection of autologous dendritic cells and activated T cells to treat patients with advanced cancers. Ann N Y Acad Sci 2009, 1174:41-50.

25. Steinman RM, Turley S, Mellman I, Inaba K: The induction of tolerance by dendritic cells that have captured apoptotic cells. J Exp Med 2000, 191:411-416.

26. Dhodapkar MV, Steinman RM, Krasovsky J, Munz C, Bhardwaj N: Antigenspecific inhibition of effector T cell function in humans after injection of immature dendritic cells. J Exp Med 2001, 193:233-238.

27. Drutman SB, Trombetta ES: Dendritic cells continue to capture and present antigens after maturation in vivo. J Immuno/ 2010, 185:2140-2146.

28. De Vries IJ, Krooshoop DJ, Scharenborg NM, Lesterhuis WJ, Diepstra JH, Van Muijen GN, Strijk SP, Ruers TJ, Boerman OC, Oyen WJ, Adema GJ, Punt CJ, Figdor CG: Effective migration of antigen-pulsed dendritic cells to lymph nodes in melanoma patients is determined by their maturation state. Cancer Res 2003, 63:12-17.

29. Singh R, Bandyopadhyay D: MUC1: a target molecule for cancer therapy. Cancer Biol Ther 2007, 6:481-486.

doi:10.1186/1477-7819-12-390

Cite this article as: Kobayashi et al:: Therapeutic effect of intratumoral injections of dendritic cells for locally recurrent gastric cancer: a case report. World Journal of Surgical Oncology 2014 12:390.

\section{Submit your next manuscript to BioMed Central and take full advantage of:}

- Convenient online submission

- Thorough peer review

- No space constraints or color figure charges

- Immediate publication on acceptance

- Inclusion in PubMed, CAS, Scopus and Google Scholar

- Research which is freely available for redistribution 